\title{
Effect of Cutting Parameters on Chips and Burrs Formation With Traditional Micromilling and Ultrasonic Vibration Assisted Micromilling
}

\section{Zhonghang Yuan}

Qilu University of Technology (Shandong Academy of Sciences)

Bin Fang ( $\nabla$ fb@qlu.edu.cn)

Qilu University of Technology (Shandong Academy of Sciences)

\section{Yuanbin Zhang}

Qilu University of Technology (Shandong Academy of Sciences)

\section{Fei Wang}

Qilu University of Technology (Shandong Academy of Sciences)

\section{Research Article}

Keywords: Traditional micromilling, Ultrasonic vibration assisted micromilling, Simulation, Burr, Chip

Posted Date: July 13th, 2021

DOI: https://doi.org/10.21203/rs.3.rs-694948/v1

License: (9) This work is licensed under a Creative Commons Attribution 4.0 International License. Read Full License

Version of Record: A version of this preprint was published at The International Journal of Advanced Manufacturing Technology on January 3rd, 2022. See the published version at https://doi.org/10.1007/s00170-021-08468-3. 


\title{
Effect of cutting parameters on chips and burrs formation with traditional micromilling and ultrasonic vibration assisted micromilling
}

\author{
Zhonghang Yuan ${ }^{1,2}$, Bin Fang ${ }^{1,2, *}$, Yuanbin Zhang1,2, Fei Wang ${ }^{1,2}$ \\ ${ }^{1}$ School of Mechanical and Automotive Engineering, Qilu University of \\ Technology (Shandong Academy of Sciences), Jinan, Shandong, 250353, \\ China; ${ }^{2}$ Shandong Institute of Mechanical Design and Research, Jinan, \\ Shandong, 250353, China
}

\begin{abstract}
In the traditional micromilling(TMM) of Inconel718 alloy, due to the influence of material plas ticity and size effect, relatively large burr will be produced. In order to solve the burr proble $\mathrm{m}$ in micromilling, ultrasonic vibration in feed direction is applied to the workpiece to complet e vibration cutting. Combined with trajectory simulation and cutting experiment, the burr forma tion mechanism of TMM and ultrasonic vibration assisted micromilling(UVAMM) was studied. The results show that when the ratio of amplitude $(A)$ to feed per tooth $\left(f_{\mathrm{z}}\right)$ is greater than 0.5 , continuous cutting changes to intermittent cutting. Compared with TMM, UVAMM improves ch ip breaking ability, facilitates the propagation of burr crack and effectively inhibits the formatio $\mathrm{n}$ of burr. However, due to the influence of cutting edge radius, $A / f_{\mathrm{z}}$ should be set larger. Wh en the chip breaking condition is reached, the burr shape is usually tearing or flocculent. Unde $\mathrm{r}$ the conditions of low speed $(n)$, large $f_{\mathrm{z}}$ and large $A$, the burr suppression is more obvious.
\end{abstract}

Keywords: Traditional micromilling; Ultrasonic vibration assisted micromilling; Simulation; Burr; Chip

*Corresponding author. E-mail address: fb@qlu.edu.cn

\section{Introduction}

Inconel718 alloy has excellent high temperature strength, high temperature oxidation resistance and corrosion resistance. It is favored by aerospace, ship, automobile and military industries [1-3]. Micromilling is an important processing method that can be used to manufacture micro-scale precision parts [4], and is also the most commonly used precision processing method for machining hightemperature nickel-based alloy materials. However, Inconel718 is easy to produce large burrs in the process of micro milling due to its large plasticity, adhesion and chip breaking, which seriously affects the assembly accuracy and performance of parts [5].

The main factors affecting the formation of burrs are tool parameters, workpiece material, processing method and cutting parameters, as shown in Fig. 1. Hashimura et al. [6] classified the burr types into top burr, entrance burr, exit burr, entrance side burr and exit side burr according to the position of the workpiece where the burr is located, as shown in Fig. 2. In order to suppress the generation of burrs, some scholars have done a lot of research by optimizing processing parameters. Li et al. [7] found 
that burrs tend to appear on the top of the groove at lower speed $(n)$, lower feed per tooth $\left(f_{\mathrm{z}}\right)$ and higher cutting depth $\left(a_{\mathrm{p}}\right)$. Lee et al. [8,9] found that large burrs are likely to occur when the cutting thickness is smaller than the cutting edge radius. Sun et al. [10] studied the groove top burr of 304 austenitic stainless steel and concluded that the size of the burr on the down milling side is larger than that on the up milling side. Hajiahmadi [11] studied the influence of $a_{\mathrm{p}}, n$ and $f_{\mathrm{z}}$ on the size of the burr, and optimized the process parameters reasonably. Mian et al. [12] found that the ratio of $f_{\mathrm{z}}$ to the cutting edge radius is the most important factor in the thickness of the burr. Yao et al. [13] reported that the size of the top burr is closely related to specific cutting energy and impeded by reducing cutting energy with the cutting parameters of optimization. In addition to optimizing processing parameters, burrs can be also suppressed by changing cutting conditions. Oliveira et al. [14] found that a higher flow of cutting fluid can effectively inhibit the formation of burrs. However, the use of cutting fluid will not only inevitably cause pollution problems, but also increase the cost. Some scholars suggested the method of low temperature pre-cooling to suppress the formation of burrs [15]. Although the burrs are effectively suppressed, it also increases tool wear. In the traditional micromilling process, surface defects and burrs are usually removed by postprocessing. Schubert et al. [16] chose to use electrochemical polishing technology to remove the generated groove top burrs and found that although the burrs can be effectively removed, the machined surface suffered a height loss of $2 \mu \mathrm{m}$. In addition, the technology to reduce burrs includes traditional micromilling(TMM) which will produce new burrs, laser technology which may burn the surface of the workpiece, micropeening which is only applied to higher hardness steel and ultrasonic wet peening which may lead to the longer cleaning time $[17,18]$. Therefore, the minimization and control of burrs are the key for micromilling to improve the surface quality of the workpieces and lower the machining cost.

Vibration assisted machining is a machining method in which external energy is applied to the tool or workpiece during the cutting process to generate high frequency vibration. At present, vibration cutting has been widely used in turning, milling, drilling and other cutting processes. It has excellent performance in reducing cutting force and cutting temperature [19-21], inhibiting tool wear [22], improving surface quality [23-26] and improving surface performance [27]. Geng et al. [28] studied the effect of rotating ultrasonic ellipse machining (RUEM) on the formation and suppression of carbon fiber reinforced plastic (CFRP) delamination and found that RUEM can effectively suppress the delamination of CFRP. Gao et al. [29] studied the chip morphology characteristics of longitudinal torsional ultrasonic assisted drilling (LTUAD), and found that LTUAD can improve the chip breaking capacity and produce more broken chips. Xiang et al. [30] used ultrasonic vibration assisted cutting(UVAC) to process Nomex honeycomb core material and found that UVAC greatly improved burrs and tearing defects of the incision. The results of these studies show that vibration cutting changes the material removal mechanism, which is beneficial to suppress the formation of burrs.

In this work, ultrasonic vibration was introduced into the micromilling process of Inconel718 to achieve the purpose of suppressing the formation of burrs. The trajectory equation of the tool tip was built and the chip interruption mechanism was analyzed during the ultrasonic vibration assisted micromilling(UVAMM). At the same time, the high-temperature nickel-based alloys is processed with TMM and UVAMM. Combined with the chip breaking conditions, the morphology and size change of chip and burr under different cutting parameters are analyzed. 


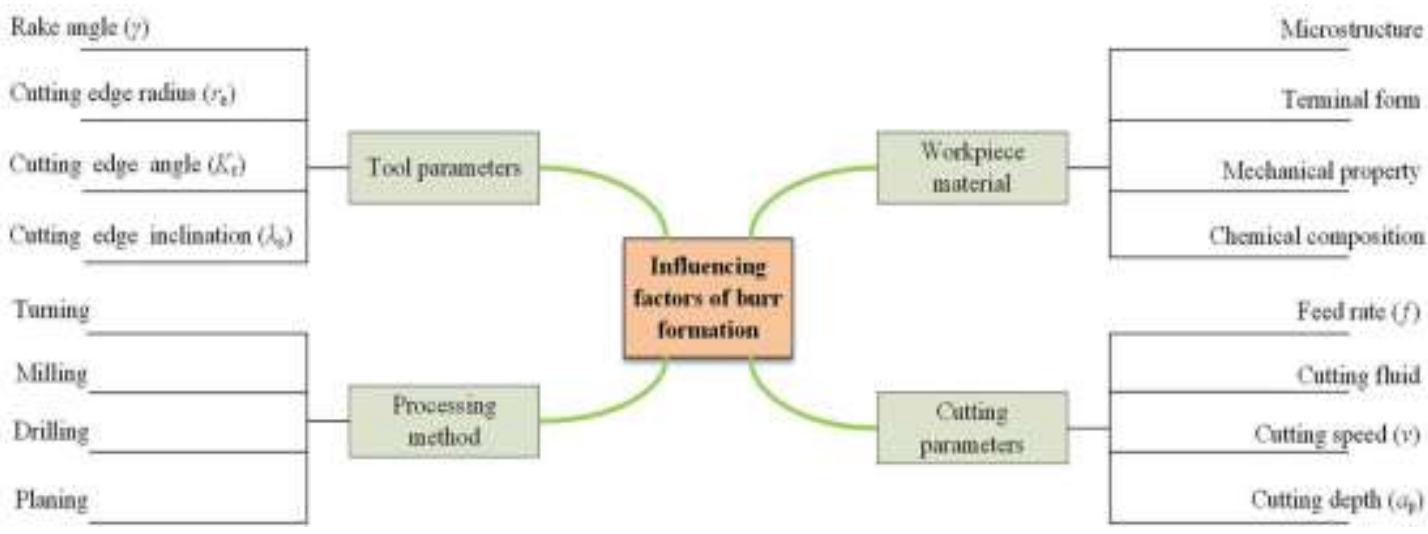

Fig. 1. Influencing factors of burr formation.

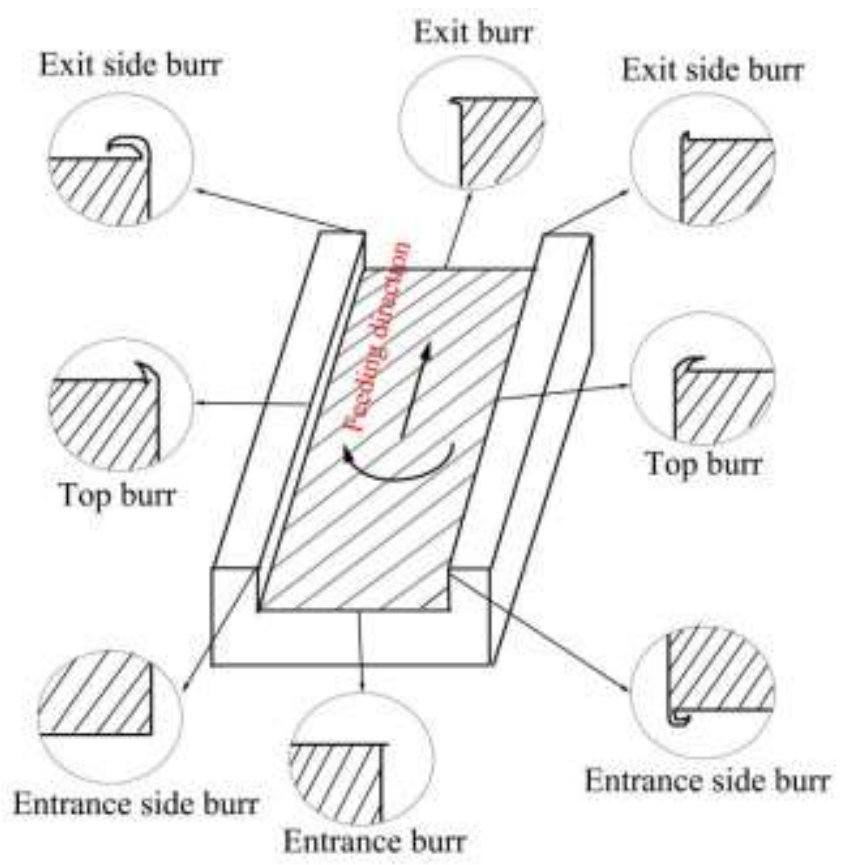

Fig. 2. Burrs type.

\section{Analysis of micromilling process}

\subsection{Chip formation process}

In micromilling processing, burrs are caused by incomplete formation or incomplete fracture of chips. As shown in Fig. 3, the formation of chips is divided into three stages, including elastic deformation stage, elastic-plastic deformation coexisting stage and plastic deformation stage. On the up milling side, when the cutting thickness is less than the minimum thickness, the material will be elastic deformation and no chips can be formed. When the cutting thickness increases to $h_{\min }$ or even greater, chips begin to form and the material recovery phenomenon still exists. However, it will not return to the original position. With the increase of cutting thickness, plastic shear deformation of materials becomes the main 
deformation form. On the down milling side, the cutting thickness is continuously reduced. When the cutting thickness is reduced to a certain value, the chips will break or stay on the top of the groove. Therefore, the burr on the up milling side is the product of extrusion deformation, and the burr on the down milling side is the product of incomplete chip fracture. In a single cutting cycle, the condition of chip formation is that the instantaneous cutting thickness is greater than the minimum cutting thickness. The simplified diagram of chip is shown in Fig. 3. When the cutting edge radius and material are determined, the minimum cutting thickness is a constant value. The minimum cutting thickness of Inconel718 is expressed by Eq.(1) [31] and the instantaneous cutting thickness is expressed by Eq.(2).

$$
\begin{aligned}
& h_{\text {min }}=0.25 r_{e} \\
& h(\theta)=f_{z} \sin (\theta)
\end{aligned}
$$

When the instantaneous cutting thickness is equal to the minimum cutting thickness, Eq.(1) and Eq.(2) can be combined to obtain Eq.(3). The chip length is expressed by Eq.(4). According to the equation, the chip length is proportional to $f_{\mathrm{z}}$.

$$
\begin{gathered}
\theta=\arcsin \left(\frac{0.25 r_{e}}{f_{z}}\right) \\
L=\left[1-\left(\frac{\arcsin \left(0.25 r_{e} / f_{z}\right)}{90}\right)\right] \pi r
\end{gathered}
$$

Where $h_{\min }$ is the minimum cutting thickness; $h$ is the instantaneous cutting thickness; $r_{\mathrm{e}}$ is the cutting edge radius; $\theta$ is the rotation angle; $L$ is the chip length; $r$ is the tool radius.

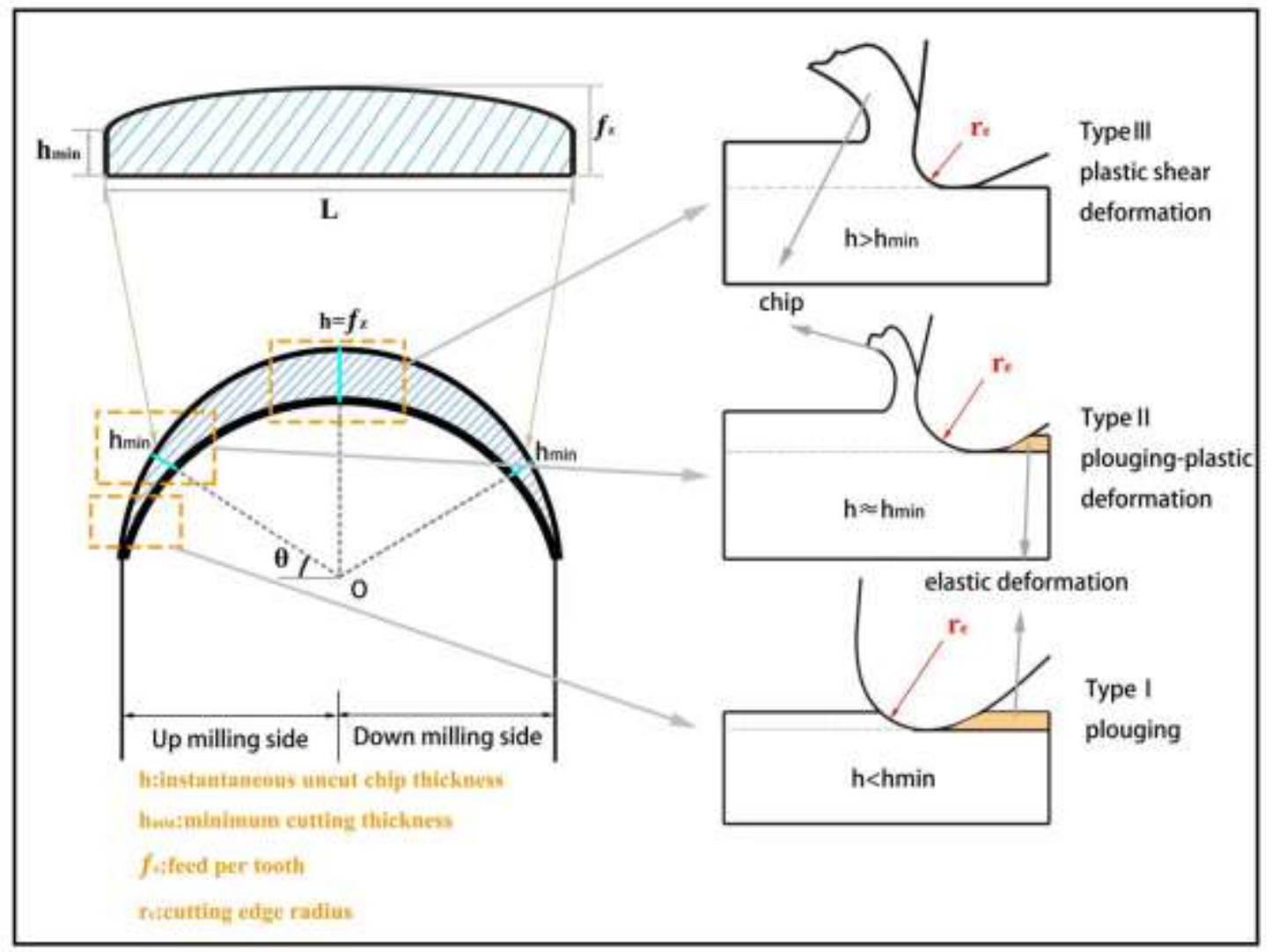

Fig. 3. Micromilling chip formation process in a single cutting cycle. 


\subsection{Trajectory equation of cutting edge}

Compared with TMM, the application of ultrasonic vibration changes the trajectory of the tool tip, which in turn affects the way chips are formed. Therefore, the analysis of tool tip trajectory is the basis of chip formation. Fig. 4 shows the trajectory of two adjacent tool tips in a motion cycle in TMM. The solid line and the dashed line represent the movement trajectory of the tool tip 1 and the tool tip 2, respectively.

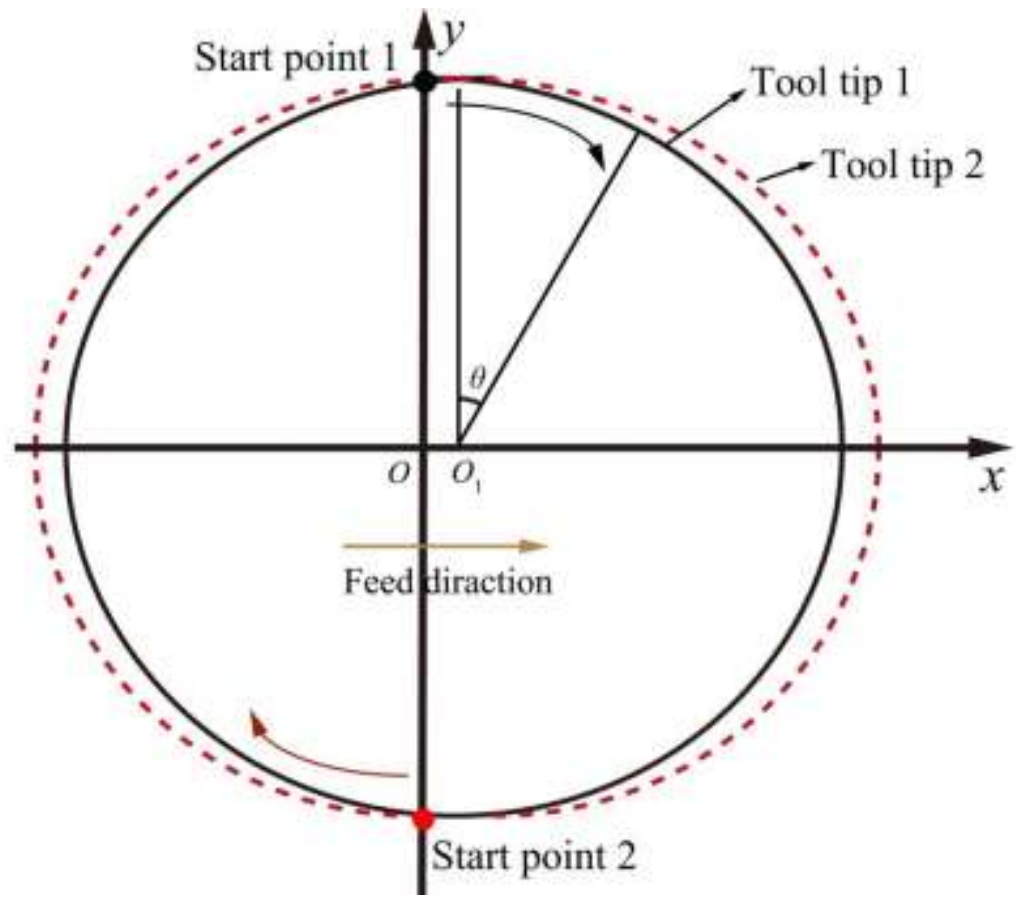

Fig. 4. Schematic diagram of tool tip path.

The motion trajectory of the tool tip is a compound motion of rotation and feed motion. According to the coordinate system established in Fig. 4, the motion of the $i$ th $(i=1,2)$ tool tip can be expressed by Eq.(5) and Eq.(6).

$$
\begin{gathered}
x_{i}=v_{f} t+(-1)^{i-1} r \sin (2 \pi n t) \\
y_{i}=(-1)^{i-1} r \cos (2 \pi n t)
\end{gathered}
$$

The vibration signal is applied to the workpiece through the ultrasonic equipment, which can realize the ultrasonic vibration in the feeding direction. In order to express the relative positional relationship between the tool tip and the workpiece more intuitively, the vibration of the workpiece is equivalent to the sinusoidal motion of the tool in the feed direction. The motion trajectory of the $i$ th tool tip can be expressed by Eq.(7) and Eq.(8).

$$
\begin{gathered}
x_{i}=v_{f} t+(-1)^{i-1} r \sin (2 \pi n t)+A \sin (\lambda \omega t) \\
y_{i}=(-1)^{i-1} r \cos (2 \pi n t)
\end{gathered}
$$

Where $v_{f}$ is the feed rate; $n$ is the spindle speed; $r$ is the tool radius; $\lambda$ is the ratio of the vibration frequency to the spindle rotation frequency; $\omega$ is the ultrasonic vibration angular frequency. 


\section{Experimental procedure}

\subsection{Experimental materials}

The micromilling cutter is the cemented carbide double-edged flat end mill with UT coating, as shown in Fig. 5. The tool geometry parameters are shown in Table 1. The workpiece material is Inconel718 alloy, and its chemical composition is shown in Table 2.

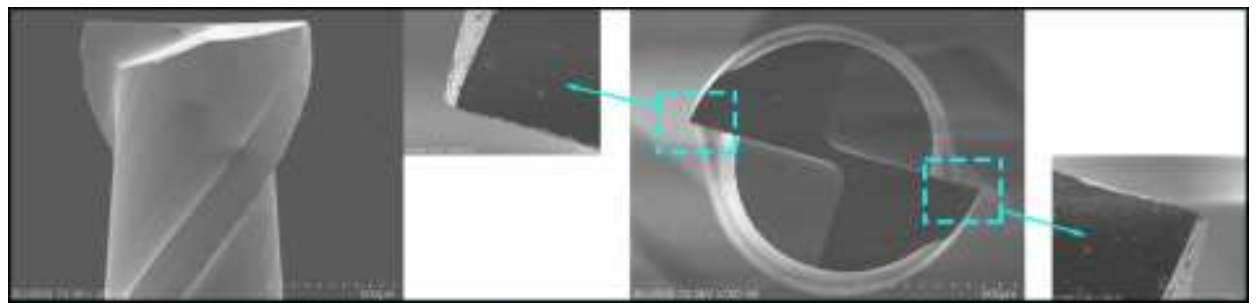

Fig. 5. Shape of micromilling cutter (SEM).

Table 1 Geometrical parameters of micromilling tool.

\begin{tabular}{ccccc}
\hline Geometrical characteristic & Parameter value & Geometrical characteristic & Parameter value \\
\hline Tool diameter $(\mathrm{mm})$ & 1 & Rake angle of side edge $\left(^{\circ}\right)$ & 0 \\
Blade length $(\mathrm{mm})$ & 4 & Rear angle of side edge $\left(^{\circ}\right)$ & 9 \\
Cutting edge radius $(\mu \mathrm{m})$ & 5 & First rear angle of base edge $\left(^{\circ}\right)$ & 9 \\
Helical angle $\left({ }^{\circ}\right)$ & 36 & Second rear angle of base edge $\left(^{\circ}\right)$ & 16 \\
\hline
\end{tabular}

Table 2 Main chemical components of Inconel 718.

\begin{tabular}{ccccccc}
\hline Element & $\mathrm{Ni}$ & $\mathrm{Cr}$ & $\mathrm{Fe}$ & $\mathrm{Nb}$ & $\mathrm{S}$ & $\mathrm{Ti}$ \\
\hline $\mathrm{wt} \%$ & 54.59 & 19.16 & 18.66 & 4.85 & 1.69 & 1.05 \\
\hline
\end{tabular}

\subsection{Experimental equipment and arrangement}

The cutting experiment was carried out on a four-axis precision milling machine(UCAR-DPCNC4S) with a speed range of 500-24000 r/min. The ultrasonic vibration device(USM-300A) provides vibration energy for the workpiece with the maximum amplitude $(A)$ of $15 \mu \mathrm{m}$. The vibrator was connected through the upper connecting plate. The machine table was connected through the lower connecting plate. A new micromilling tool was used to machine a groove on the surface of the workpiece. The experimental equipment and arrangement are shown in Fig. 6. The machining parameters are shown in Table 3. 


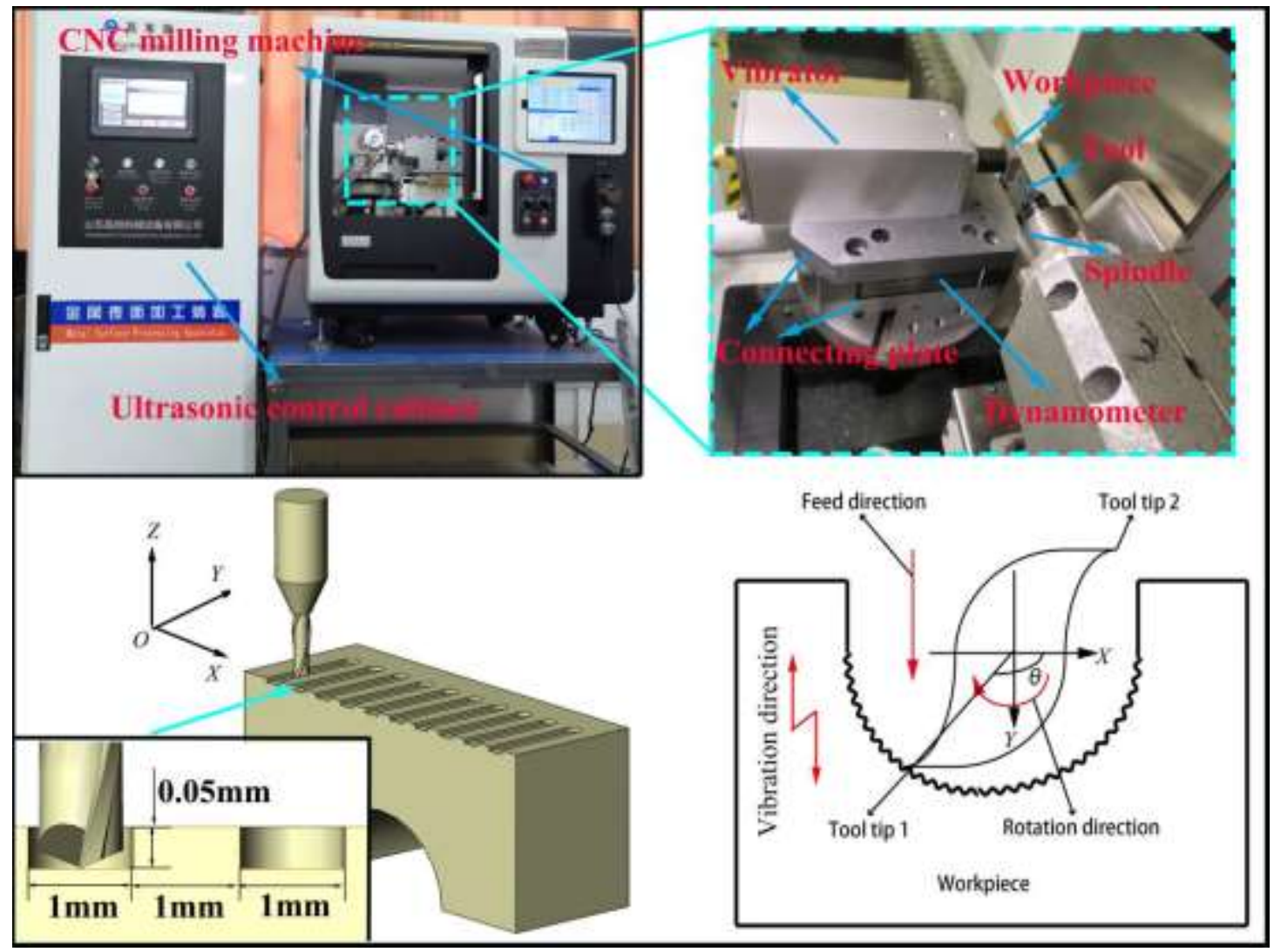

Fig. 6. Experimental device and experimental design.

Table 3 Machining parameters

\begin{tabular}{|c|c|c|c|c|c|}
\hline Experiment number & $\begin{array}{l}\text { Spindle speed } \\
n\left(10^{3} \mathrm{r} / \mathrm{min}\right)\end{array}$ & $\begin{array}{c}\text { Cutting depth } \\
\qquad a_{\mathrm{p}}(\mu \mathrm{m})\end{array}$ & $\begin{array}{l}\text { Feed per tooth } \\
\qquad f_{\mathrm{z}}(\mu \mathrm{m} / \mathrm{z})\end{array}$ & $\begin{array}{l}\text { Amplitude } \\
\qquad A(\mu \mathrm{m})\end{array}$ & $\begin{array}{c}\text { Vibration } \\
\text { frequency } \\
f(\mathrm{kHz})\end{array}$ \\
\hline \multirow{4}{*}{ Experiment 1} & 6 & \multirow{4}{*}{50} & \multirow{4}{*}{6} & 0 & \multirow{4}{*}{32} \\
\hline & 12 & & & 3 & \\
\hline & 18 & & & 6 & \\
\hline & 24 & & & 9 & \\
\hline \multirow{7}{*}{ Experiment 2} & \multirow{7}{*}{6} & \multirow{7}{*}{50} & 2 & & \multirow{7}{*}{32} \\
\hline & & & 3 & 0 & \\
\hline & & & 4 & & \\
\hline & & & 5 & & \\
\hline & & & 6 & \multirow{3}{*}{9} & \\
\hline & & & 7 & & \\
\hline & & & 8 & & \\
\hline
\end{tabular}

The chips and burrs are investigated with a super-high magnification lens zoom 3D microscope and scanning electron microscope(SEM). In order to obtain the burr size accurately, the burr is measured by the super high magnification lens zoom 3D microscope. The measuring method is shown in Fig. 7. The 
width and height of burr on both sides of the groove were measured at the different 20 position, and the average width and height of burr were calculated according to Eq.(9) and (10).

$$
\begin{gathered}
B_{w}=\frac{1}{20} \sum_{i=1}^{20} \Delta w_{i} \\
B_{h}=\frac{1}{20} \sum_{i=1}^{20} \Delta h_{i}
\end{gathered}
$$

Where $B_{w}$ is the average of burr width; $B_{h}$ is the average value of burr height; $\Delta w_{i}$ is the burr width of the $i$ point; $\Delta h_{i}$ is the burr height of the $i$ point.
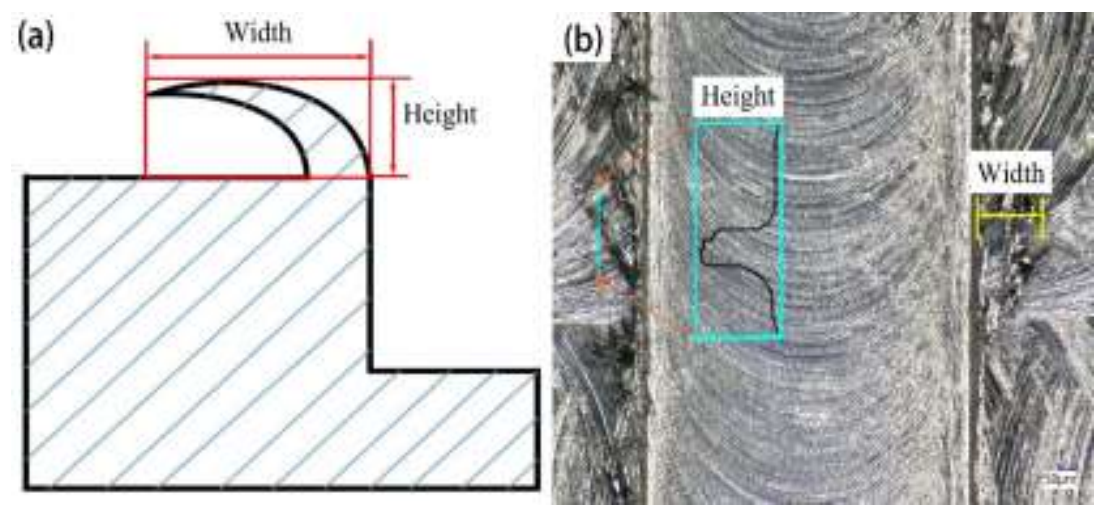

Fig. 7. Measurement of burr(a): Schematic diagram of burr measurement; (b): Burr measurement by microscope.

\section{Results and discussion}

\subsection{Trajectory of cutting edge}

In the machining process of UVAMM, $f_{\mathrm{z}}$ and $A$ are the most important parameters to change the formation mechanism of chip and burr, so it is very important to judge the relationship between $f_{\mathrm{z}}$ and $A$ by analyzing the tool tip trajectory. According to the tool tip trajectory model, the motion trajectories of the tool tips with different parameters are shown in Fig. 8. It can also be seen from Fig. 8(a-c) that when the $A$ is $3 \mu \mathrm{m}$, there are the significant intersections of tool tip trajectory between tool tip1 and tool tip2, which indicates that the chip breaking is the result of the combined effect of the $A$ and $f_{\mathrm{z}}$. It can be seen from the tool tip trajectory in Fig. 8(d-f) that when the $A$ increases from 0 to $3 \mu \mathrm{m}$, the tool tip trajectory begins to intersect, and the chips may or have been broken. As the $A$ increases from 3 to $6 \mu \mathrm{m}$, there are the significant intersections of tool tip trajectory between tool tip1 and tool tip2, which indicates that the chip is no longer continuous. According to the characteristics of the tool tip trajectory, it can be concluded that the motion trajectory of the tool tip 2 and the tool tip 1 intersects when $A / f_{\mathrm{z}}>1 / 2$, which can meet the chip breaking requirements. Shen et al. [20,21] also simulated the motion trajectory of the tool tip, and the results showed that when the tool tip trajectory intersects, the cutting process changes to intermittent cutting. 
(a)

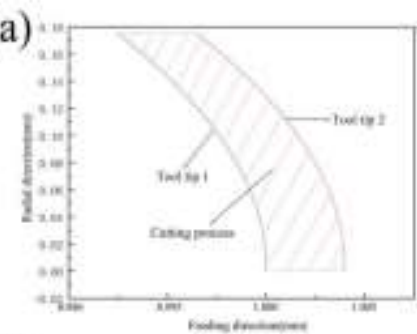

(d)

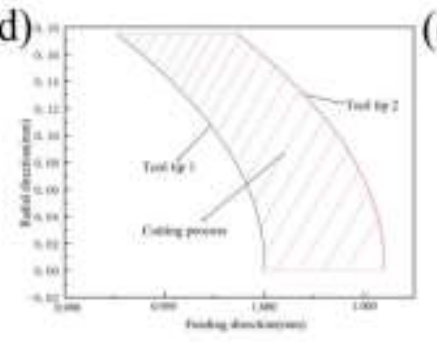

(b)

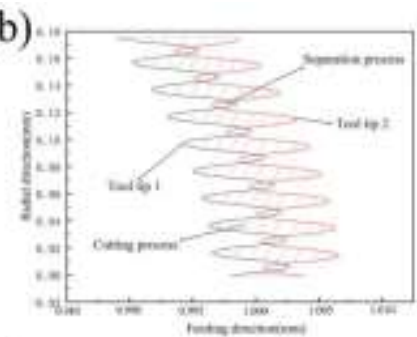

(e)

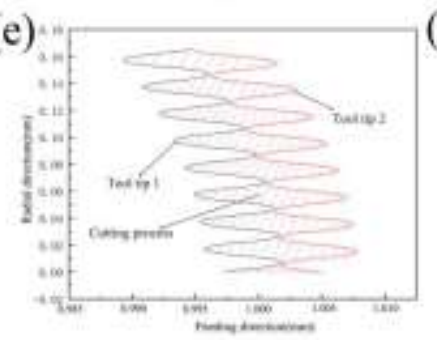

(c)

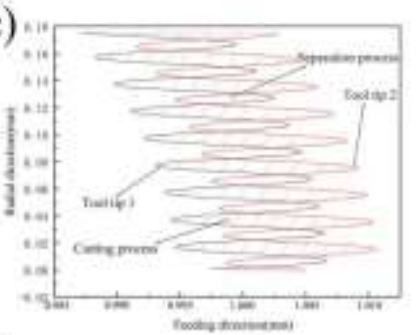

(f)

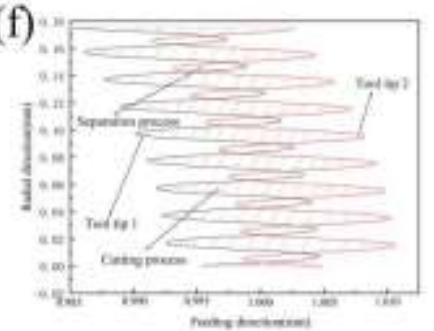

Fig. 8. Simulation of tool tip trajectory(a): $f_{\mathrm{z}}=4 \mu \mathrm{m} / \mathrm{z}, A=0 \mu \mathrm{m}$; (b): $f_{\mathrm{z}}=4 \mu \mathrm{m} / \mathrm{z}, A=3 \mu \mathrm{m}$; (c): $f_{\mathrm{z}}=4 \mu \mathrm{m} / \mathrm{z}, A=6 \mu \mathrm{m}$; (d): $f_{\mathrm{z}}=6 \mu \mathrm{m} / \mathrm{z}, A=0 \mu \mathrm{m}$; (e): $f_{\mathrm{z}}=6 \mu \mathrm{m} / \mathrm{z}, A=3 \mu \mathrm{m}$; (f): $f_{\mathrm{z}}=6 \mu \mathrm{m} / \mathrm{z}, A=6 \mu \mathrm{m}$.

\subsection{Influence of cutting parameters on chip size}

Burr is the product of incomplete chip fracture. Research on chip formation is the basis for research on burr formation.

Fig. 9 shows the chip morphology of TMM and UVAMM under different $n$. It can be seen from the figure that when the ultrasonic vibration is not applied, the chips with long size and spiral shape are produced. After the ultrasonic vibration is applied, the spiral chip is gradually transformed into C-type chip, which is most obvious when $A / f_{\mathrm{Z}}>1 / 2$. At this time, the cutting mode changes from continuous cutting to intermittent cutting.

Fig. 10 shows the variation of chip size of TMM and UVAMM under different $n$. The maximum chip size is $1865 \mu \mathrm{m}$ when $n$ is $6000 \mathrm{r} / \mathrm{min}$. With the increase of $n$, the chip size first decreases and then increases, and the trends of chip size is similar for the amplitude of 0 and 3um. According to the simulation of tool tip trajectory, there is not intersection between tool tip1 and tool tip2 on the condition of the amplitude of 0 and 3um, which lead to the similar mode of the chip breaking. In addition, the separation between the tool tip and workpiece is beneficial for the chip breaking on the condition of the amplitude of 3um, which decreases the chip size. However, chip size of the amplitude of 6 and 9um is obviously smaller than that of the amplitude of 0 and $3 \mathrm{um}$. There exist the significant intersection between Tool tip1 and tool tip2 on the condition of the amplitude of 6 and 9um and is prone to easily break the chips. When ultrasonic vibration is applied, the chip size decreases obviously, especially at low $n$. The reason is that the lower $n$ will lead to more vibration times in the same distance, so chip breaking is more frequent. With the increase of $n$, the time of ultrasonic vibration per unit distance decreases, which lead to decline the vibration effect of the cutting process. 


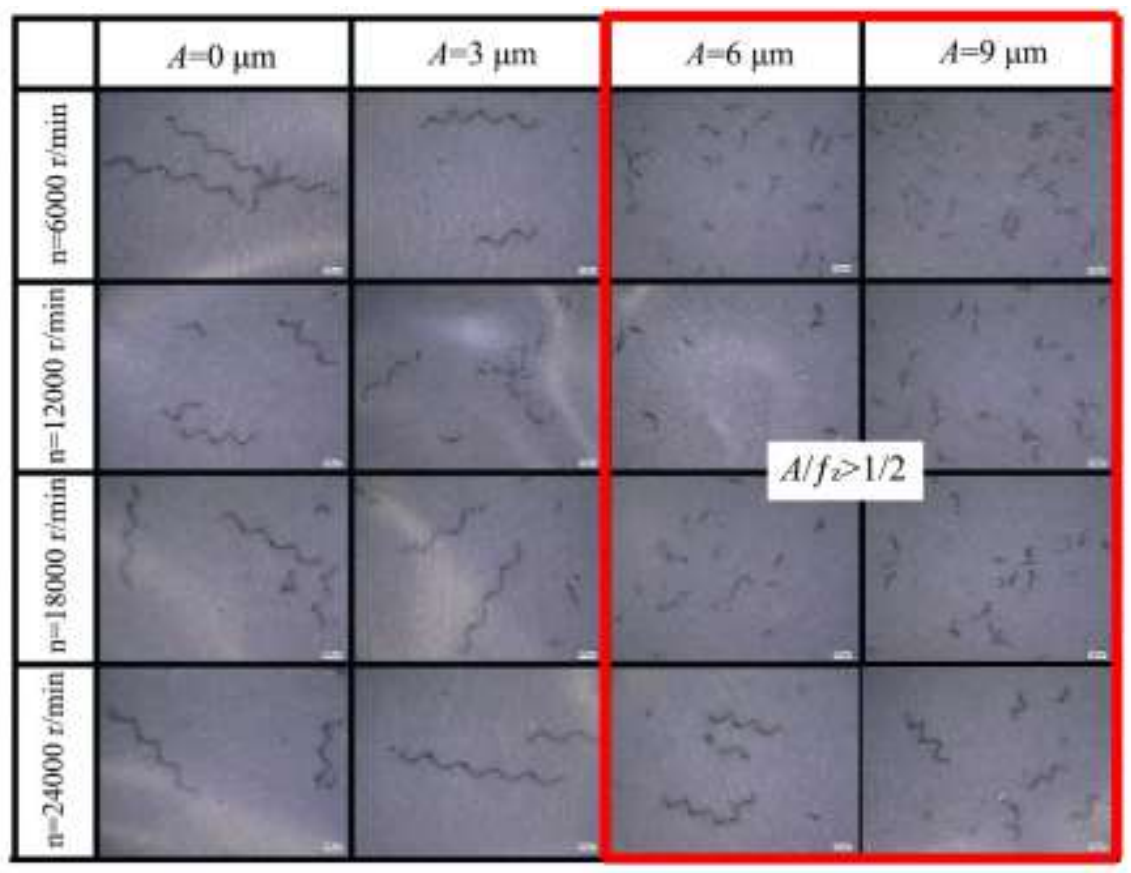

Fig. 9. Chip morphology under different $n$. $\left(f_{z}=6 \mu \mathrm{m} / \mathrm{z}, \quad a_{p}=50 \mu \mathrm{m}\right)$

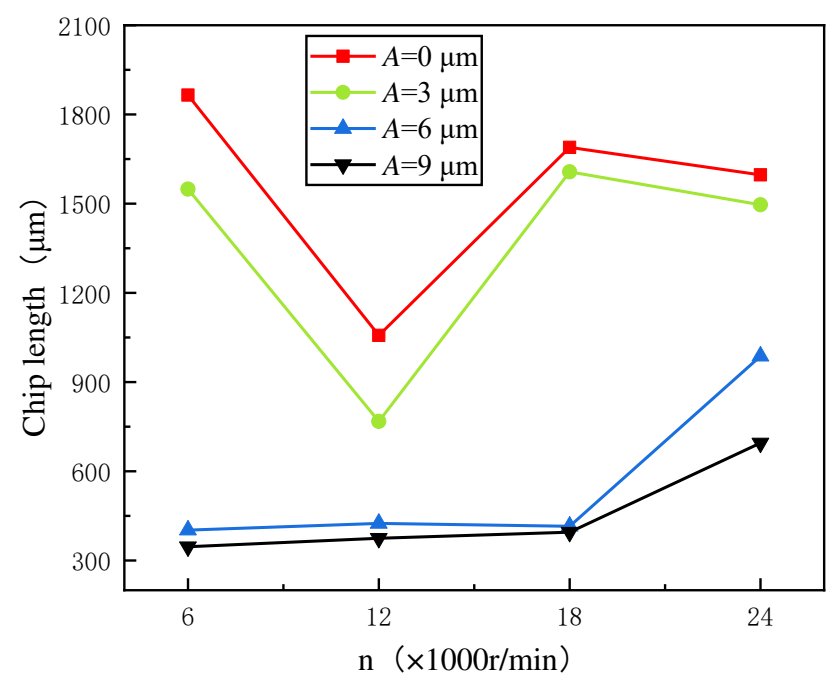

Fig. 10. Change of chip size under different $n .\left(f_{z}=6 \mu \mathrm{m} / \mathrm{z}, a_{p}=50 \mu \mathrm{m}\right)$

Fig. 11 shows the chip morphology of TMM and UVAMM under different $f_{\mathrm{z}}$. It can be $\mathrm{s}$ een from the figure that when the ultrasonic vibration is not applied, a large number of C-sha ped chips or serrated chips are easily generated with a small $f_{\mathrm{z}}$. However, when $f_{\mathrm{z}}$ is more th an $5 \mu \mathrm{m} / \mathrm{z}$, long and spiral chips are produced. The reason is that when $f_{\mathrm{z}}$ is small, the mater ial must be accumulated to a certain thickness before it is sheared and removed[32,33]. When ultrasonic vibration is applied, high frequency intermittent cutting changes the instantaneous cutt ing thickness, reduces the influence of size effect, and makes chip formation and breaking easi er. It can be seen from the figure that the number of C-type chips increases after applying vib 
ration. When $A$ is $3 \mu \mathrm{m}$ and $f_{\mathrm{z}}$ is small, spiral chip appears. The reason is that the $A$ is too small and the chip breaking effect is not obvious. When $A$ is more than $3 \mu \mathrm{m}$, the chip is co mpletely transformed into C-type chip. The larger the $A$ is, the more broken the chip is.

Fig. 12 shows the variation of chip size of TMM and UVAMM under different $f_{\mathrm{z}}$. When the ultrasonic vibration is not applied, the chip size increases with the increase of $f_{\mathrm{z}}$. When $f_{\mathrm{z}}$ is in the range of $2-4 \mu \mathrm{m} / \mathrm{z}$, the chip formation is difficult and the size and quantity of chips is small due to the size effect. However, the chip size dramatically increase in TMM when $f_{\mathrm{z}}$ is larger than $6 \mu \mathrm{m}$. It is also found that the trend of chip size is similar when $A$ is 6 and $9 u$, which indicate that the larger $A$ is beneficial for the chip-broken. When $f_{\mathrm{z}}$ is larger, the chip size of UVAMM is obviously smaller than that of TMM. The larger $A$ is, the smaller chip size is. However, the effect of $f_{z}$ on chip size is no longer obvious in UVAMM. Ultrasonic vibration plays an important role in chip breaking. It is prone to the chip breaking of smaller $n$, larger $f_{\mathrm{z}}$ and $A$ in the micromilling.

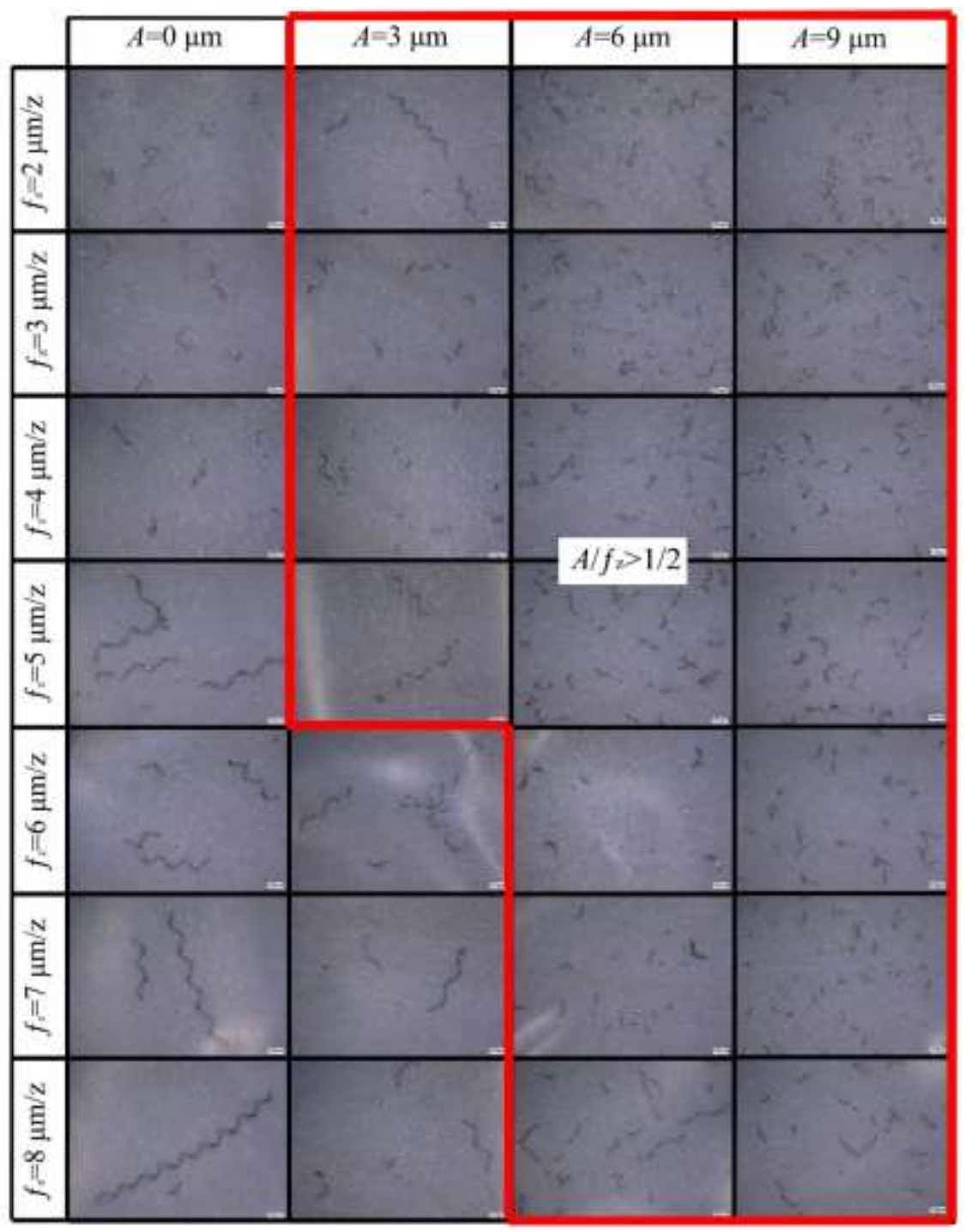

Fig. 11. Chip morphology under different $f_{\mathrm{z}} .\left(n=12000 \mathrm{r} / \mathrm{min}, a_{p}=50 \mu \mathrm{m}\right)$ 


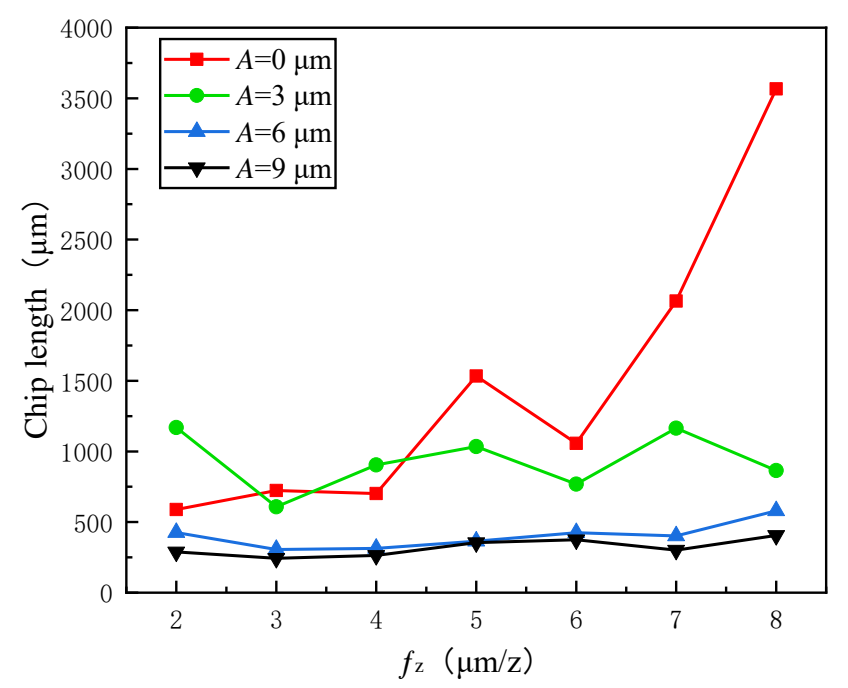

Fig. 12. Change of chip size under different $f_{\mathrm{z} .}\left(n=12000 \mathrm{r} / \mathrm{min}, a_{p}=50 \mu \mathrm{m}\right)$

\subsection{Influence of cutting parameters on burr size}

In order to study the influence of ultrasonic vibration on burr formation, the milling groove morphology was taken by scanning electron microscope, as shown in Fig. 13 and Fig. 15. In the figures, the upper side of the milling groove is the down milling side, and the lower side is the up milling side.

Fig. 13 shows the burr morphology of TMM and UVAMM at different $n$. When the ultrasonic vibration is not applied, the burr on the down milling side is flaky, and the burr on the up milling side is long strip. When $n$ is $6000 \mathrm{r} / \mathrm{min}$, the flaky burr on down milling side is large, smooth and complete. The strip burr on up milling side is large and the quantity is large. With the increase of $n$, the flaky burr curls and the strip burr turns into flaky burr. When the ultrasonic vibration is applied, the flaky burr on the down milling side is gradually transformed into tearing burr, and the strip burr on the up milling side is gradually transformed into flocculent burr.

Fig. 14 shows the variation of burr size of TMM and UVAMM under different $n$. Through the analysis of the burr size, it is found that when $n=6000 \mathrm{r} / \mathrm{min}$, the burr size on both sides of the groove top is the largest, in which the width and height of the burr on the down milling side are $123 \mu \mathrm{m}$ and 69 $\mu \mathrm{m}$ respectively, and the width and height of the burr on the up milling side are $256 \mu \mathrm{m}$ and $125 \mu \mathrm{m}$ respectively. With the increase of $n$, the width and height of the burr on the down milling side decrease first and then increase, while the width and height of the burr on the up milling side decrease. The reason is that with the increase of $n$, the extrusion and friction time of the up milling side is shortened, and the plastic deformation is reduced, so the burr size is also reduced. However, the thermal softening effect caused by the increase of cutting temperature on the down milling side is obvious, and the chips are difficult to break and remain on the top of the groove. After the ultrasonic vibration is applied, the burr size of both the down milling side and the up milling side decreases significantly, especially at low 
$n$. When the $A$ is $3 \mu \mathrm{m}$, the variation trend of burr size of UVAMM is the same as that of TMM. When the high-frequency chip-broken condition is reached, the burr size decreases more obviously, and the change trend is different from that of TMM. The reason is that the application of ultrasonic vibration can increase the chip breaking frequency and reduce the chip size, thus reducing the burr size.

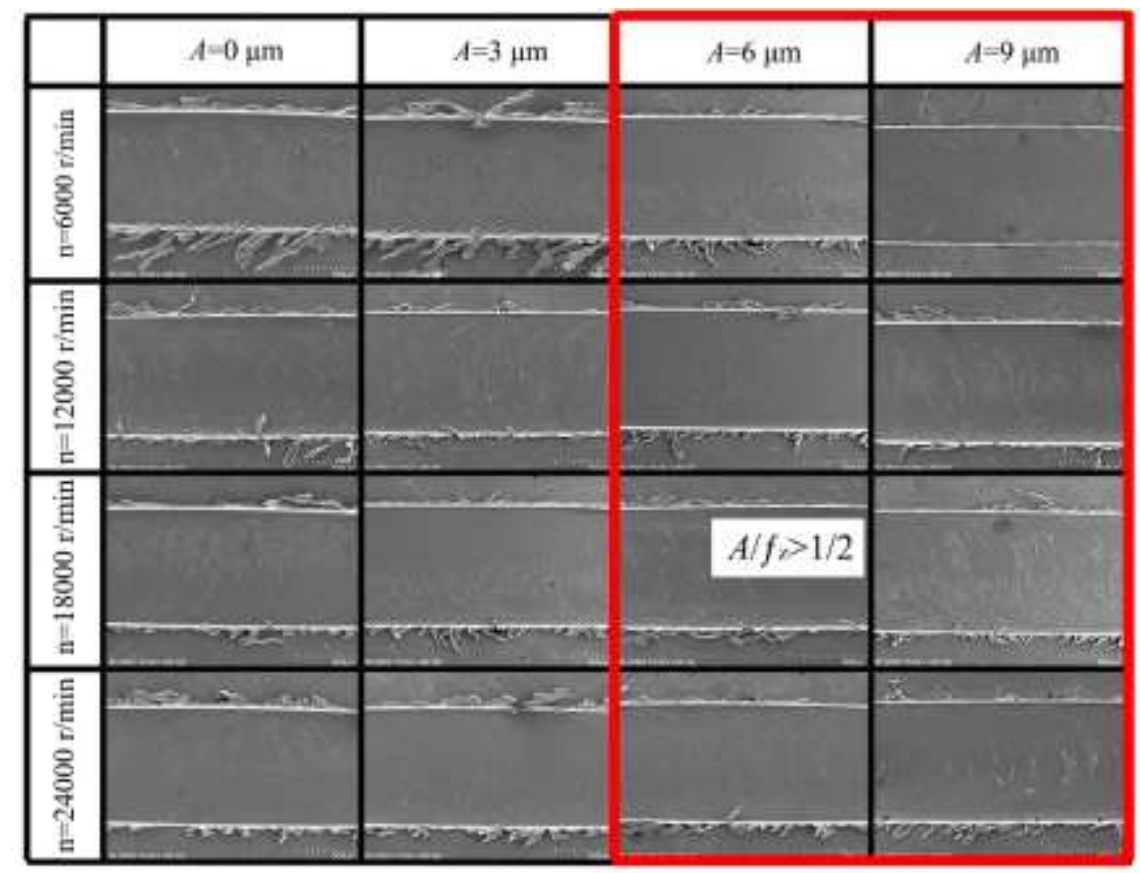

Fig. 13. Morphology of burr under different $n$ (SEM). $\left(f_{z}=6 \mu \mathrm{m} / \mathrm{z}, \quad a_{p}=50 \mu \mathrm{m}\right)$
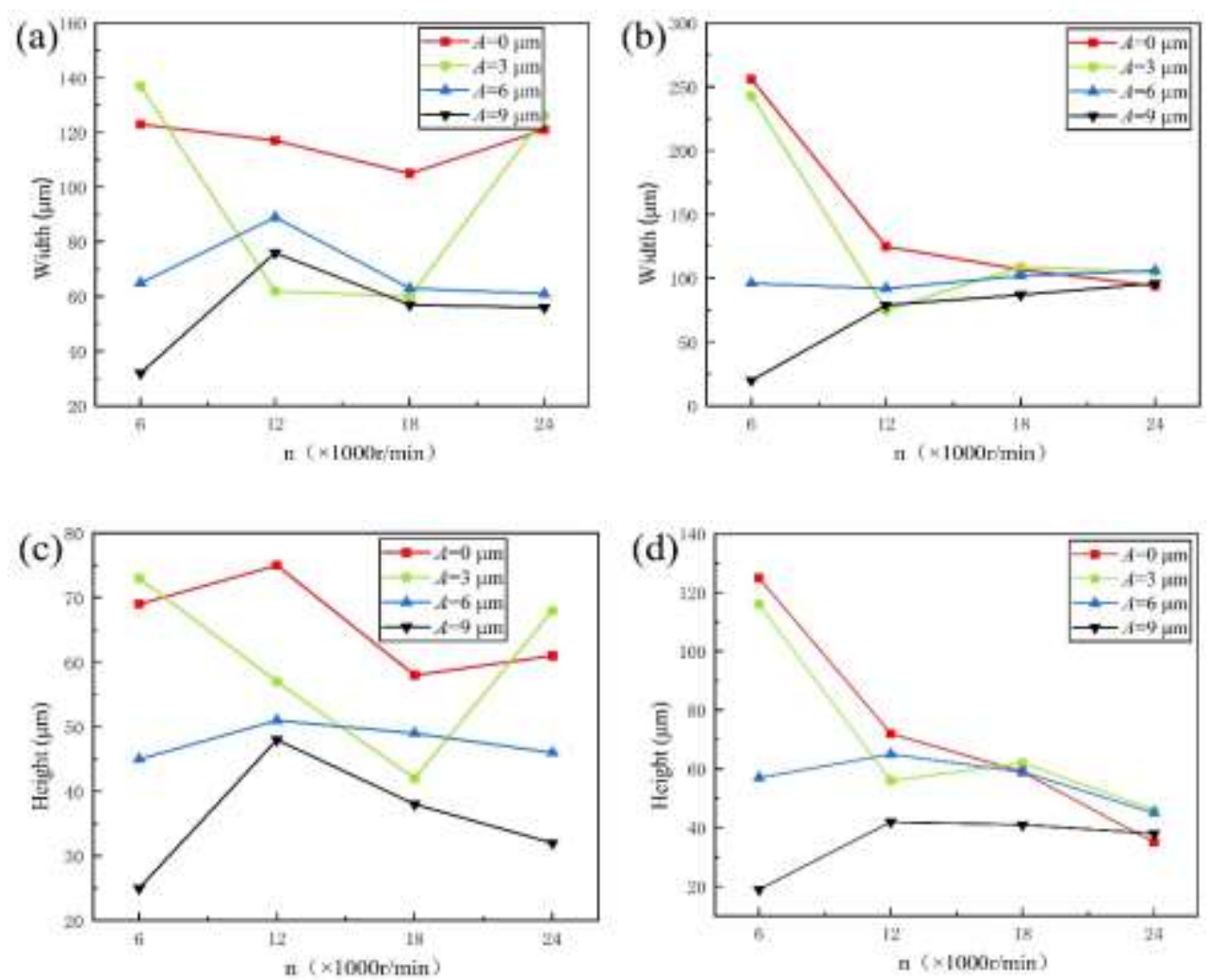
Fig. 14. Variation of burr size under different $n(\mathrm{a})$ : Burr width of down milling side; (b): Burr width of up milling side; (c): Burr height of down milling side; (d): Burr height of up milling side. $\left(f_{z}=6 \mu \mathrm{m} / \mathrm{z}\right.$, $\left.a_{p}=50 \mu \mathrm{m}\right)$

Fig. 15 shows the burr morphology of TMM and UVAMM under different $f_{\mathrm{z}}$. When the ultrasonic vibration is not applied, the chip is difficult to produce because $f_{\mathrm{z}}$ is small. In this case, the burr on the down milling side is the result of incomplete chip fracture, and the burr on the up milling side is the result of ploughing. Therefore, smaller flake burr will be produce $\mathrm{d}$ on the down milling side, while flocculent burr will be produced on the up milling side. Wi th the increase of $f_{\mathrm{z}}$, the flake burr changes into turning burr, and the flocculent burr changes into larger strip burr. The reason is that with the increase of $f_{\mathrm{z}}$, the volume of material remov ed per unit time increases, and the cutting force also increases, so the plastic deformation of material is more serious, leading to the increase of burr. After the vibration is applied, the chi $\mathrm{p}$ breaking ability is improved and the extrusion effect is reduced. Therefore, the burr on the down milling side is gradually changed into tearing burr, and the burr on the up milling side is also gradually changed into flocculent burr, especially at high feed rate.

Fig. 16 shows the variation of burr size of TMM and UVAMM under different $f_{\mathrm{z}}$. When the ultrasonic vibration is not applied, the width and height of both sides of the groove top in crease with the increase of $f_{\mathrm{z}}$. After the vibration is applied, the instantaneous cutting thicknes $\mathrm{s}$ is obviously changed, the influence of size effect is reduced, the formation and separation of chips are easier, and the burr is well restrained, especially when the feed rate is large. Howe ver, when $f_{\mathrm{z}}$ is $8 \mu \mathrm{m} / \mathrm{z}$, the influence of ultrasonic vibration on burr size is not obvious. The reason is that the larger $f_{\mathrm{z}}$ is, the smaller $A / f_{\mathrm{z}}$ is. Although $A / f_{\mathrm{z}}>1 / 2$, the size effect is still ve ry important due to the influence of cutting edge radius. When $f_{\mathrm{z}}$ is small, ultrasonic vibration can suppress the formation of burr by reducing the influence of size effect and changing the way of chip formation. When $f_{\mathrm{z}}$ is larger, ultrasonic vibration can suppress the formation of $\mathrm{b}$ urr by changing the instantaneous cutting thickness and improving the ability of chip breaking.

Combined with the formation characteristics of chip and burr, it can be found that burr a nd chip are closely related, and improving the ability of chip breaking plays an important role in burr suppression. 


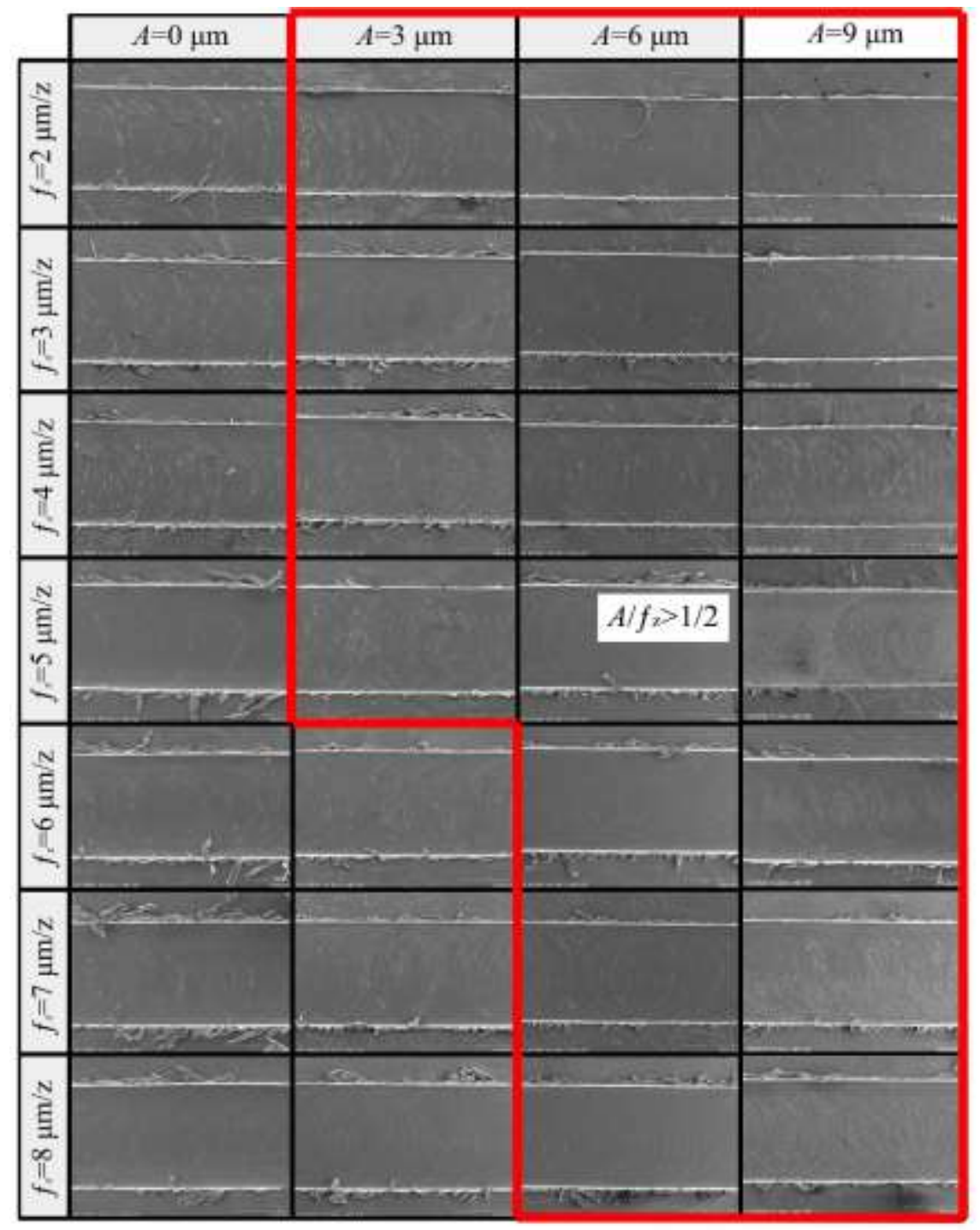

Fig. 15. Morphology of burr under different $f_{\mathrm{z}}$ (SEM). $\left(n=12000 \mathrm{r} / \mathrm{min}, a_{p}=50 \mu \mathrm{m}\right)$
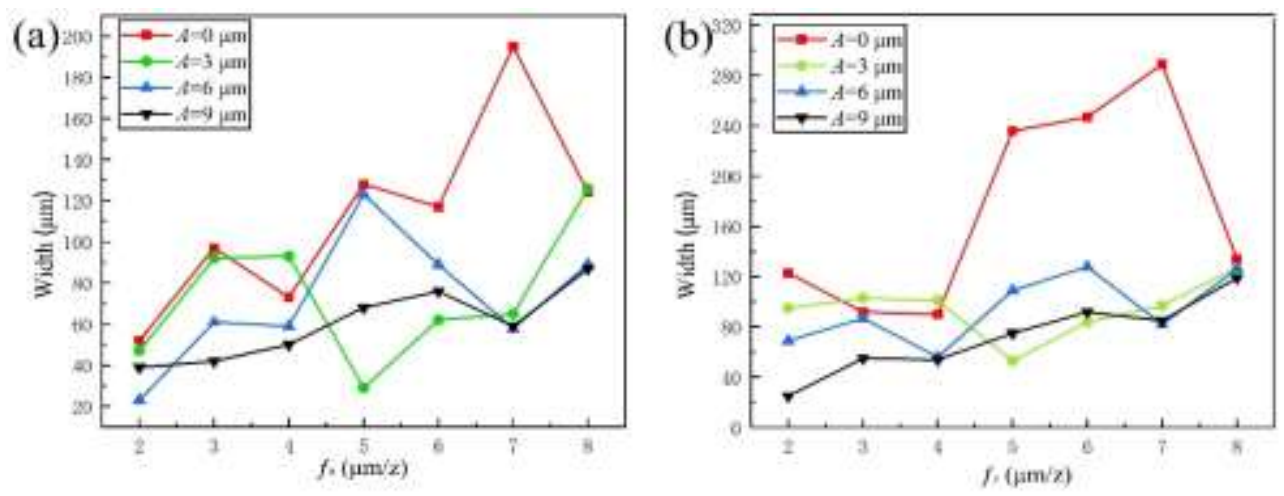

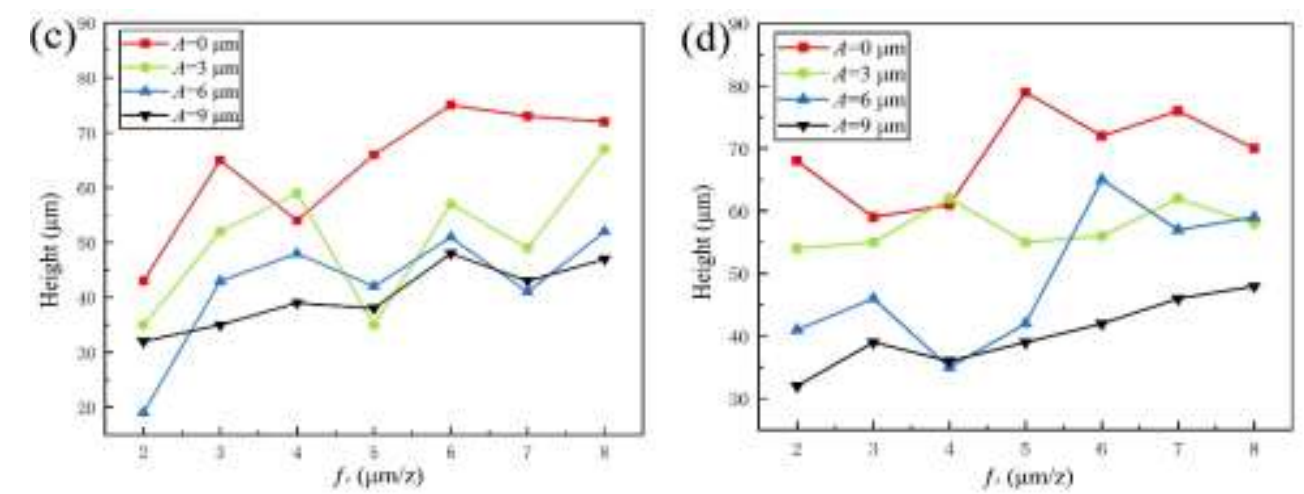

Fig. 16. Variation of burr size under different $f_{\mathrm{z}}$ (a): Burr width of down milling side; (b): Burr width o $\mathrm{f}$ up milling side; (c): Burr height of down milling side; (d): Burr height of up milling side. ( $n=12000 \mathrm{r}$ / $\left.\min , a_{p}=50 \mu \mathrm{m}\right)$

\subsection{Morphology characteristics of burr in UVAMM}

Fig. 17 shows the burr morphology of TMM and UVAMM. It can be seen from Fig. 17(a), due to the high plasticity of the material, the material is continuously accumulated and bent under the influence of cutting force, thus forming a spiral burr with wide texture on the down milling side. Due to the influence of extrusion effect, the burr with dense texture and flaky shape is formed on the up milling side. After ultrasonic vibration is applied, due to the influence of high frequency vibration, the burr with dense texture and tearing shape is produced on the down milling side and the burr with dense texture and flocculent is produced on the up milling side. With the increase of $A$, the damage effect of the cutting tool on the material is more severe, and the cracks at the edge of the burr continue to expand, thus forming more broken burr, as shown in Fig. 17(b) and Fig. 17(c). Chen et al. [34] found that UVAMM is beneficial to the generation of cracks and the formation of chips in the cutting area. This conclusion can explain the formation of burr morphology mentioned above. 

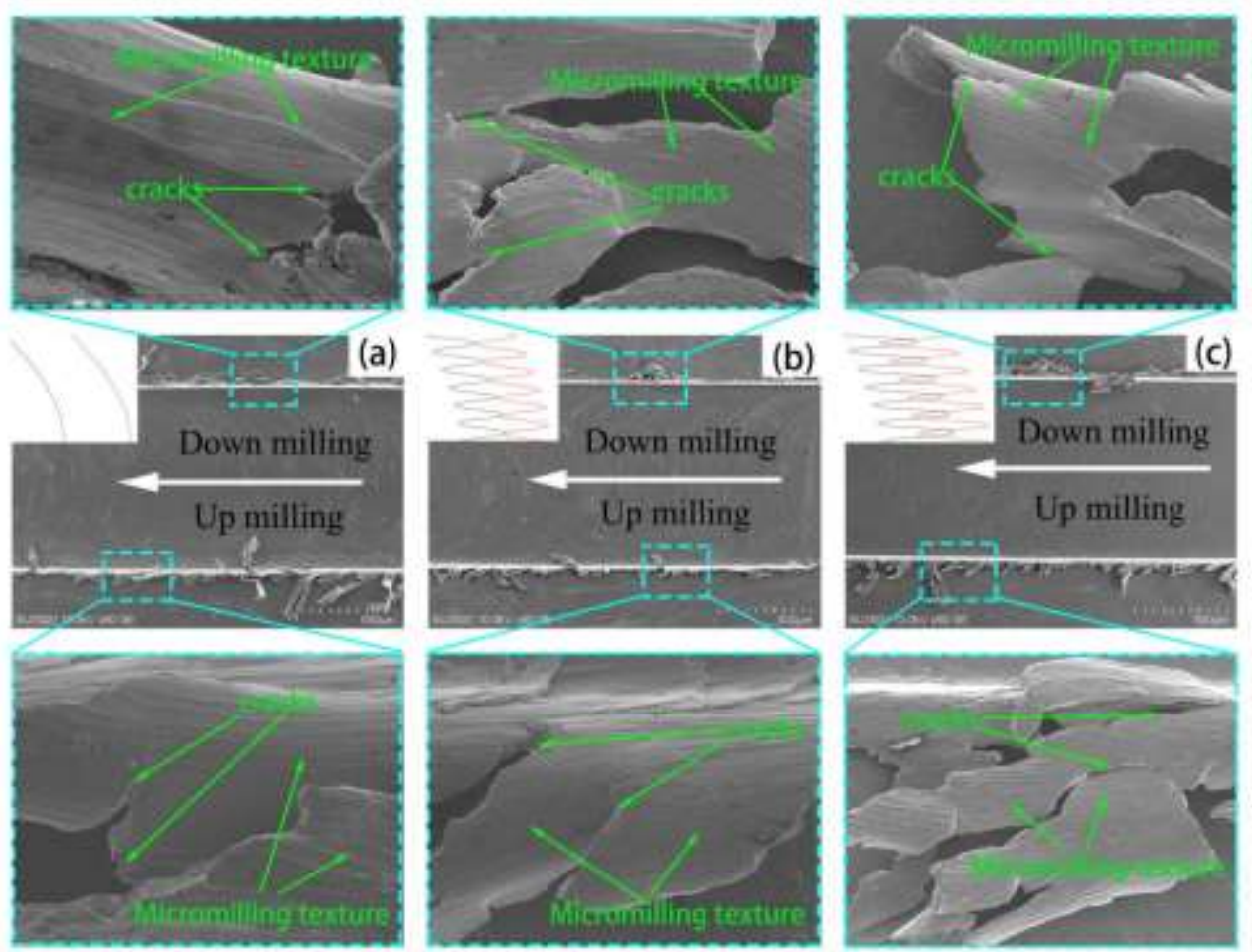

Fig. 17. Burr morphology(a): $A=0 \mu \mathrm{m}$; (b): $A=3 \mu \mathrm{m}$; (c): $A=6 \mu \mathrm{m}$. $\left(n=12000 \mathrm{r} / \mathrm{min}, a_{p}=50 \mu \mathrm{m}, f_{\mathrm{z}}=6 \mu \mathrm{m} / \mathrm{z}\right)$

\section{Conclusions}

In this study, Inconel718 was machined by TMM and UVAMM, and the influence of ultrasonic vibration on burr was analyzed. The main findings are summarized as follows:

(1) When the ratio of $A$ to $f_{z}$ is greater than 0.5 , continuous cutting changes to intermittent cutting. At this time, the spiral chip gradually changes into C-type chip.

(2) Combining trajectory simulation and cutting experiment, it is found that UVAMM can effectively reduce the chip size and burr size. By observing the change of chips and burrs, it is found that there is an relate relationship between chip and burr. Under the conditions of low $n$, large $f_{\mathrm{z}}$ and large amplitude, the burr suppression is more obvious.

(3) When ultrasonic vibration is applied, denser textures and longer cracks appear on the burr surface. With the increase of amplitude, the burr suppression effect is more obvious.

Funding This reseach was supported by National Natural Science Foundation of China (52075275), Agricultural Key Applied Project of China (SD2019NJ015) and Project for the Innovation Team of Universities and Institutes in Jinan of China (2018GXRC005).

Competing interests The authors declare that they have no competing interests.

Data Availability Not applicable. 
Code availability Not applicable.

Ethics approval Not applicable.

Consent to participate Not applicable.

Consent for publication Not applicable.

Authors' contributions Not applicable.

\section{References}

[1] Liu Y, Guo Q, Li CH, Mei Y, Zhou X, Huang Y, Li H (2016) Recent progress on evolution of precipitates in Inconel 718 superalloy. Acta Metall Sin 52:1259-1266.

[2] Rahman M, Seah W, Teo T (1997) The machinability of Inconel 718. J Mater Process Tech 63:199204.

[3] Pereira O, Celaya A, Urbikaín G, Rodríguez A, Asier F, Lacalle L (2020) CO 2 cryogenic milling of Inconel 718: cutting forces and tool wear. J Mater Res Technol 9:8459-8468.

[4] Boswell B, Islam M, Davies I (2018) A review of micromechanical cutting. Int J Adv Manuf Technol $94: 1-18$

[5] Ucun İ, Aslantaş K, Bedir F (2015) The performance Of DLC-coated and uncoated ultra-fine carbide tools in micromilling of Inconel 718. Precision Engineering 41:135-144.

[6] Hashimura. M, Hassamamontr. J, Dornfeld D (1999) Effect of In-plane Exit Angle and Rake Angles on Burr Height and Thickness in Face Milling Operation, Transactions of the ASME. J Manuf Sci E-T Asme 121: 13-19.

[7] Li SH, Zou B, Xu K, Wang Y (2019) Machined channel quality and tool life using cermet micro-mill in micro-milling mluminum alloy. Int J Adv Manuf Tech 101:2205-2216.

[8] Lee K, Dornfeld D (2002) An experimental study on burr formation in micro-milling aluminium and copper. Trans NAMRI/SME 30:1-8.

[9] Lee K, Dornfeld D (2004) Micro-burr formation and minimization through process control. Precision Engineering 29: 246-252.

[10] Sun Q, Cheng X, Zhao G, Yang X, Zheng G (2019) Experimental study of micromilling burrs of 304 stainless steel. Int J Adv Manuf Tech 105:4651-4662. 
[11] Hajiahmadi S (2019) Burr size investigation in micro milling of stainless steel 316L. International Journal of Lightweight Materials and Manufacture 2:296-304.

[12] Mian A, Driver N, Mativenga P (2011) Identification of factors that dominate size effect in micromachining. Int J Mach Tool Manu 51:383-394.

[13] Yao Y, Zhu H, Huang CH, Wang J, Zhang P, Yao P (2019) Investigation on chip formation and surface integrity in micro end milling of maraging steel. Int J Adv Manuf Tech 102:1973-1984.

[14] Oliveira D, Gomes M, Silva M (2020) Influence of cutting fluid application frequency on the surface quality of micromilled slots on Inconel 718 alloy. Procedia Manufacturing 48:553-558.

[15] Ucun İ, Aslantaş K, Bedir F (2015) The effect of minimum quantity lubrication and cryogenic precooling on cutting performance in the micro milling of Inconel 718. P I Mech Eng B-J Eng 229:1-10.

[16] Schubert T, Bohn L, Mayer J, Schaller T (1999) Microstructure grooves with a width of less than 50 $\mu \mathrm{m}$ cut with ground hard metal micro end mills. Precis Eng 23:229-235.

[17] Lee S, Dornfeld D (2001) Precision Laser Deburring and Acoustic Emission Feedback. J Manuf Sci E-T Asme 123:356-364.

[18] Kienzler A, Deuchert M, Schulze V (2010) Burr Minimization and Removal by Micro Milling Strategies or Micro Peening Processes. Springer Berlin Heidelberg 237-243.

[19] Shen X, Zhang J, Yin T, Jie CH (2010) A study on cutting force in micro end milling with ultrasonic vibration. Adv Mater Res 905:1910-1914.

[20] Shen X, Wang M (2016) Finite element analysis of temperature field in vibration milling. Key Eng Mater 693:1030-1037.

[21] Shen X, Zhang J, Li H, Wang J, Wang X (2012) Ultrasonic vibration-assisted milling of aluminum alloy. Int J Adv Manuf Tech 63:41-49.

[22] Ni CH, Zhu L, Yang ZH (2019) Comparative investigation of tool wear mechanism and corresponding machined surface characterization in feed-direction ultrasonic vibration assisted milling of Ti-6Al-4V from dynamic view. Wear 436-437:1-17.

[23] Sajjady S, Abadi H, Amini S, Nosouhi R (2016) Analytical and experimental study of topography of surface texture in ultrasonic vibration assisted turning. Mater Design 93:311-323.

[24] Tao G, Ma CH, Bai L, Shen X, Zhang J (2017) Feed-direction ultrasonic vibration-assisted milling surface texture formation. Mater Manuf Process 32:193-198.

[25] Tao G, Zhang J, Shen X, Bai L, Ma CH, Wang J (2016) Feasibility study on ultrasonic vibration 
assisted milling for squamous surface. Procedia CIRP 42:847-852.

[26] Chen G, Ren CH, Zou Y, Qin X, Lu L, Li SH (2019) Mechanism for material removal in ultrasonic vibration helical milling of Ti6Al4V alloy. Int J Mach Tool Manu 138:1-13.

[27] Zhang M, Zhang D, Geng D, Shao ZH, Liu Y, Jiang X (2019) Effects of tool vibration on surface integrity in rotary ultrasonic elliptical end milling of Ti-6Al-4V. J Alloy Compd 821:1-10.

[28] Geng D, Liu Y, Shao ZH, Zhang M, Jiang X, Zhang D (2020) Delamination formation and suppression during rotary ultrasonic elliptical machining of CFRP. Compos Part B-Eng 183:1-12.

[29] Gao G, Xia Z, Yuan ZH, Xiang D, Zhao B (2020) Influence of longitudinal-torsional ultrasonic assisted vibration on micro-hole drilling Ti-6Al-4V. Chinese J Aeronaut. https://doi.org/10.1016/j.cja.2020.06.012.

[30] Xiang D, Wu B, Yao Y, Zhao B, Tang J (2019) Ultrasonic Vibration Assisted Cutting of Nomex Honeycomb Core Materials. Int J Precis Eng Man 20:27-36.

[31] Fang B, Yuan ZH, Li, Gao L (2020) Effect of ultrasonic vibration on finished quality in ultrasonic vibration assisted micromilling of Inconel718, Chinese J Aeronaut 34:209-219.

[32] Vogler M, DeVor R, Kapoor S (2004) On the modeling and analysis of machining performance in micro-endmilling, part I: surface generation, Journal of Manufacturing Science and EngineeringTransactions of the Asme 126:685-694.

[33] Vogler M, Kapoor S, DeVor R (2004) On the modeling and analysis of machining performance in micro-endmilling, part II: cutting force prediction, Journal of Manufacturing Science and EngineeringTransactions of the Asme 126:695-705.

[34] Chen W, Zheng L, Teng X, Yang K, Huo D (2019) Finite element simulation and experimental investigation on cutting mechanism in vibration-assisted micro-milling. Int J Adv Manuf Tech 105:45394549. 